\title{
Resistance of Tomato Line Hawaii7996 to Ralstonia solanacearum Pss4 in Taiwan Is Controlled Mainly by a Major Strain-Specific Locus
}

\author{
Jaw-Fen Wang, ${ }^{1}$ Jocelyne Olivier, ${ }^{2}$ Philippe Thoquet, $^{2}$ Brigitte Mangin, ${ }^{3}$ Laurent Sauviac, ${ }^{2}$ and \\ Nigel H. Grimsley ${ }^{2}$ \\ ${ }^{1}$ Bacteriology Unit, AVRDC, P.O. Box 42, Shanhua, Tainan, Taiwan 741; ${ }^{2}$ Laboratoire de Biologie Molécu- \\ laire des Relations Plantes-Microorganismes, CNRS-INRA, B.P. 27 Auzeville, 31326 Castanet-Tolosan, \\ France; ${ }^{3}$ Unité de Biométrie et Intélligence Artificielle, B.P. 27 Auzeville, 31326 Castanet-Tolosan, France \\ Accepted 10 September 1999.
}

\begin{abstract}
Bacterial wilt caused by the soilborne bacterium Ralstonia solanacearum attacks hundreds of plant species, including many agriculturally important crops. Natural resistance to this disease has been found in some species and is usually inherited as a polygenic trait. In tomato, a model crop plant, genetic analysis previously revealed the involvement of several QTL (quantitative trait loci) controlling resistance and, in all of these studies with different strains of the pathogen, loci on chromosome 6 played the predominant role in controlling this trait. Using quantitative data collected from a greenhouse test $F_{3}$ population, we identified a new locus on chromosome 12 that appears to be active specifically against a race 1 biovar 3 Pss4 bacterial strain endemic to Taiwan. Chromosome 6 still contributes significantly to the control of the resistance, and weaker associations of the trait to other regions of the genome are observed. These results are discussed in the context of current molecular knowledge about the strain specificity of disease resistance genes.
\end{abstract}

Additional keywords: Burkholderia solanacearum, Lycopersicon, Pseudomonas solanacearum, tolerance.

Ralstonia solanacearum is a soilborne bacterium that causes a serious disease known as bacterial wilt in hundreds of different plant species. In the natural process of infection, the bacterium, which can survive over long periods in humid soil, enters the roots of host plants at the sites of emergence of secondary roots or at root tips (Schmit 1978; Vasse et al. 1995), and after a phase of intercellular growth gains entry into the plant xylem. Once the bacterium is in the vascular system, systemic spread of the pathogen occurs, accompanied by further growth and the secretion of large quantities of extracellular polysaccharides (for a review see Buddenhagen and Kelman 1964). A variety of proteins important for the pathogenicity of the bacterium are also secreted by a specific mechanism that is known to be conserved among many plantpathogenic bacteria and shares similarities with some animal pathogen virulence mechanisms (Gough et al. 1992; for re-

Corresponding author: Nigel H. Grimsley

E-mail: grimsley@toulouse.inra.fr views see Van Gijsegem et al. 1993, Alfano and Collmer 1997). Eventually, the density of the bacterial population and the quantity of the polysaccharides present in the xylem attain high levels, impeding water flow, and the plant usually dies by wilting, permitting the bacteria to return to the soil inside collapsed leaf tissue. This process occurs over periods ranging from several days to several weeks, depending on the environmental conditions and the host plant-bacterial strain combination being studied.

Although bacterial wilt is a disease of major economic importance, little is known about the molecular mechanisms governing resistance. Natural resistance to the disease is the preferred method for the protection of crops, since soil bacteria are notoriously difficult to eliminate in an environmentally acceptable way. Resistance to $R$. solanacearum has been described in different crop plants as polygenic, and dependent upon environmental conditions (Kelman 1953; Hayward 1991). Resistant varieties may tolerate the limited growth of the bacterial pathogen within their vascular systems (Grimault et al. 1995). Recently, resistance in the model plant Arabidopsis has been described (Deslandes et al. 1998; Yang and Ho 1998). Genetic analysis of resistance in tomato (Lycopersicon esculentum) with molecular markers has been done with populations of plants produced from different crosses (Danesh et al. 1994; Thoquet et al. 1996a, 1996b; Mangin et al. 1999). Danesh et al. (1994) observed an important QTL (quantitative trait locus) close to CT184 around $40 \mathrm{cM}$ on chromosome 6 in tomato cultivar L285, and Danesh and Young (1994) showed that the resistance controlled by this locus could be specific for the type of bacterial strain. In addition, their laboratory noted the presence of QTL on chromosomes 7 and 10. The broad QTL peak found on chromosome 6 with tomato cultivar Hawaii7996 (Thoquet et al. 1996a, 1996b) could subsequently be resolved into two separate QTL (Mangin et al. 1999): one mapping in the same region as the QTL found in L285, the other (possibly environment specific) being close to the disease resistance locus $C f-2$. In a field trial, Thoquet et al. (1996b) observed weaker associations between resistance and markers on chromosomes 3, 4, 8, and 10 .

Here, we identify a new major locus carried by tomato cultivar Hawaii7996 that gives resistance to the bacterial strain Pss4 endemic to Taiwan. 


\section{RESULTS}

\section{Extension of the genetic map of the cross} Hawaii7996 $\times$ WVa700.

In order to map resistance to bacterial wilt in our population in Taiwan extension of the genetic map was necessary since we first identified a strong association between resistance and an unmapped, codominant, random amplified polymorphic DNA (RAPD) marker, K4a (Fig. 1). Our objectives were then (i) to find with which linkage group it was associated and (ii) to identify linked markers spanning the genomic region carrying this resistance.

A genetic map made from an $\mathrm{F}_{2}$ population of 200 individual descendants from the cross between resistant tomato cultivar Hawaii7996 and the susceptible line WVa700 was available (Thoquet et al. 1996a; Moreau et al. 1998; Mangin et al. 1999). This map permitted the detection of loci associated with resistance over about $3 / 4$ of the genome, but a few regions remained unmarked. We thus screened further markers that had previously been mapped in a reference population (Tanksley et al. 1992) in regions of the genome lacking markers.

Except for the RAPD marker K4, which revealed polymorphic bands associated with three different linkage groups (Fig.
1, $\mathrm{K} 4 \mathrm{a}, \mathrm{K} 4 \mathrm{~b}$, and $\mathrm{K} 4 \mathrm{c}$ ), including one codominant polymorphism associated with the trait of interest mentioned above (K4a), only restriction fragment length polymorphism (RFLP) probes were included for the analysis. As a first step in the analysis, we attempted to clone the $\mathrm{K} 4 \mathrm{a}$-specific bands in order to generate RFLP probes in the region of interest. Two types of clones were obtained. One showed polymorphism and mapped on chromosome $3(\mathrm{~K} 4 \mathrm{dRF})$, but the other was not polymorphic and thus could not be mapped in our material.

Further screening and RFLP analyses, however, led us to concentrate on chromosome 12 , and three probes linked to K4a, namely CT120, TG564, and CT156 (Fig. 1), were identified. Both CT120 and CT156, which flank the new linkage group, have been mapped previously to chromosome 12 on a densely marked reference map (Tanksley et al. 1992), and this region corresponds to a region previously unmarked on our map (Thoquet et al. 1996a). In order to find these two polymorphic landmark markers on chromosome 12, in all 30 chromosome 12-anchored markers were screened by Southern blotting after digestion with 14 restriction enzymes. The LOD $\left(\log _{10}\right.$ of the odds ratio) score for linkage between TG564 (the closest marker to the QTL) and CT120 (the closest chromosome 12 landmark) is 31.7 .

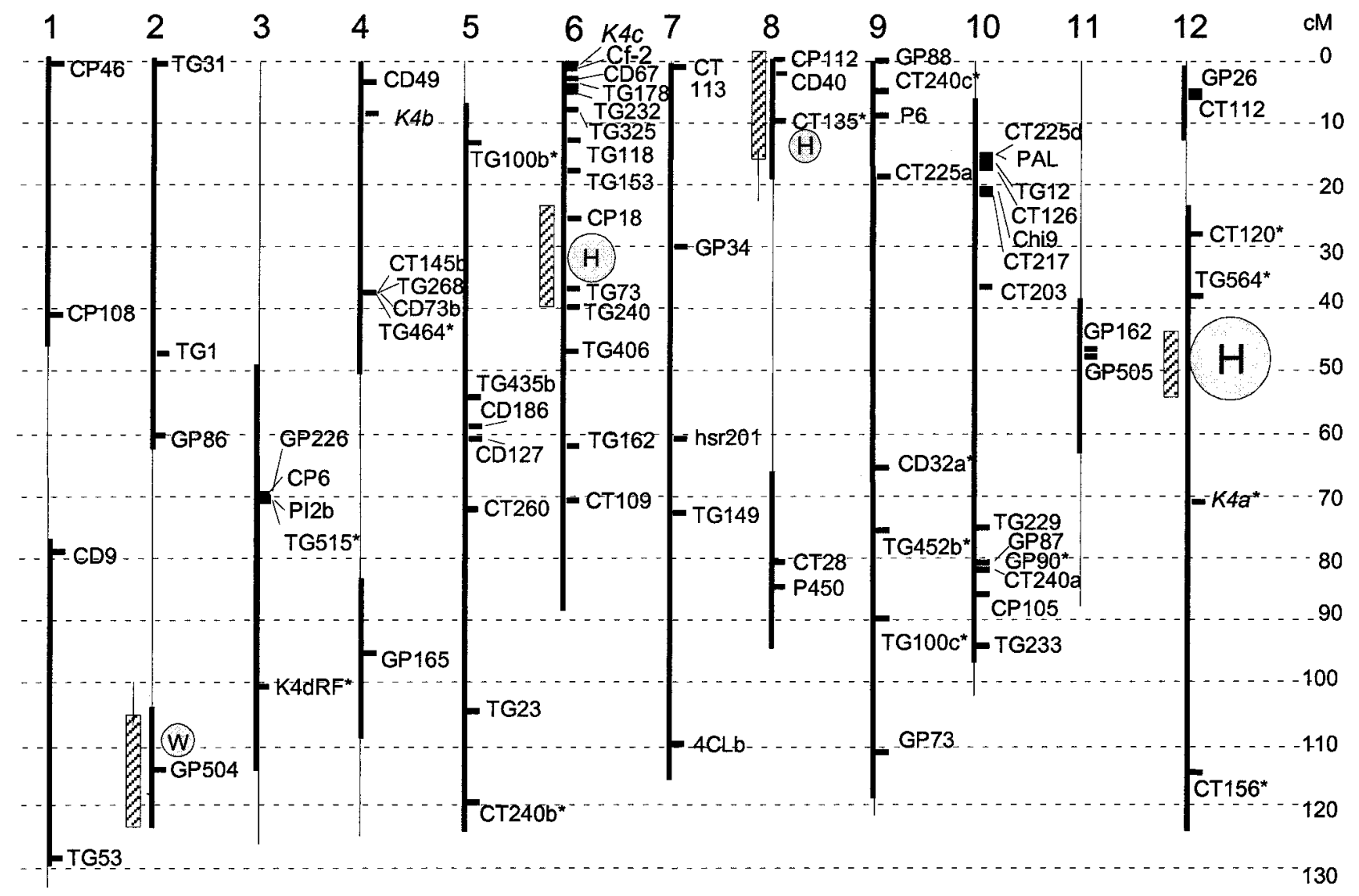

Fig. 1. Genetic map of tomato from an $F_{2}$ population of the cross Hawaii7996 $\times$ WVa700, extended from previous work (Thoquet et al. 1996a; Moreau et al. 1998). Linkage groups are indicated by bold vertical lines. Except for the random amplified polymorphic DNA (RAPD) markers K4a, K4b, and K4c, all markers are restriction fragment length polymorphisms (RFLPs). Markers mapped in this study are indicated with an asterisk.The 95\% confidence intervals for the map positions of the associations between markers and resistance are indicated by hatched bars; the size of the adjacent filled circles gives an impression of the size of the effect: $\mathrm{H}$ indicates that the allele(s) for resistance were carried by the Hawaii7996 parent; W indicates that the allele(s) for resistance were carried by the WVa700 parent. The significance levels of these associations are shown in Table 1; the weak associations observed on chromosomes 2 and 8 cannot be placed precisely (arrows). 
Overall, although the level of polymorphism was rather low (Thoquet et al. 1996a), 14 more markers were positioned, and the maps of chromosomes 5, 9, and 12 were extended, permitting about a further $150 \mathrm{cM}$ to be covered (Fig. 1).

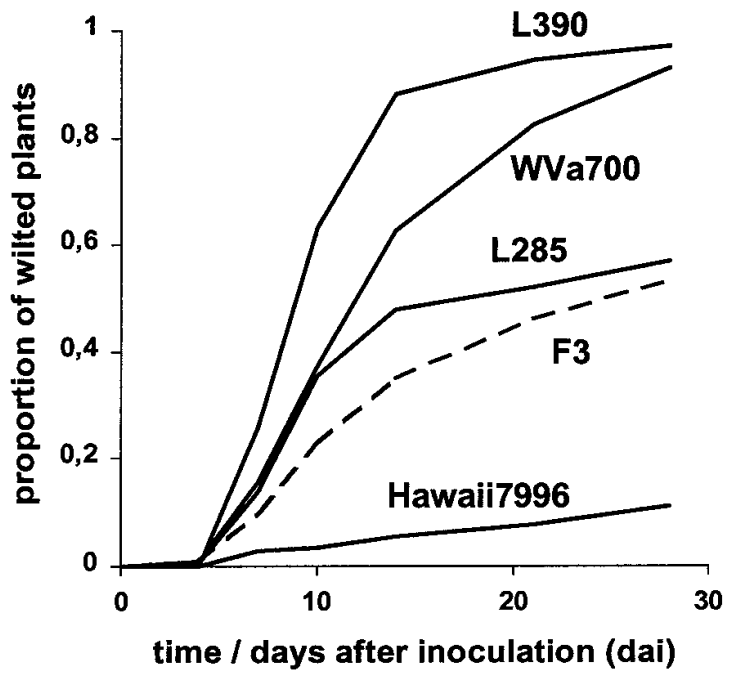

Fig. 2. Time course of symptom development.The proportions of control homozygous plant lines (continuous lines) wilting is compared alongside that of the $\mathrm{F}_{3}$ population (dotted line).

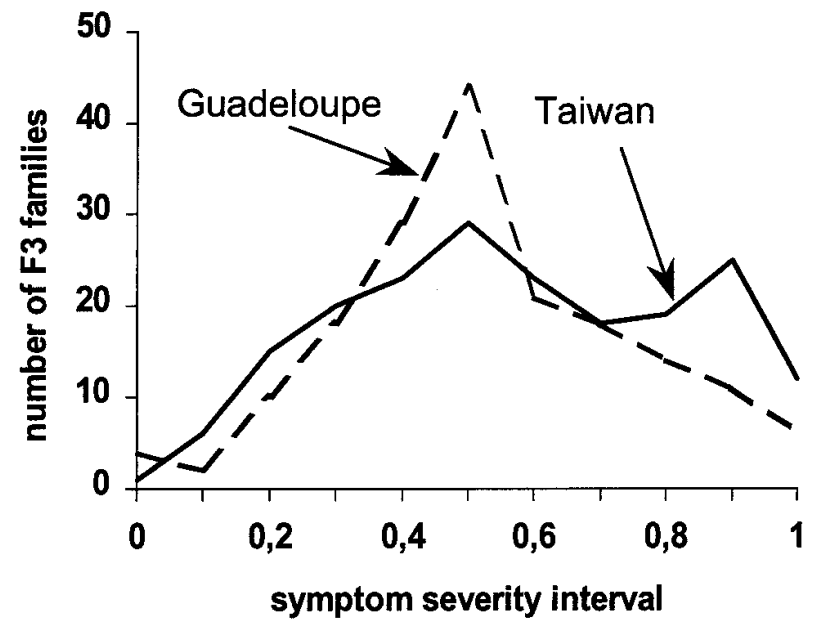

Fig. 3. Frequency distribution of symptoms in $\mathrm{F}_{3}$ populations in two geographic locations. The proportion of wilted plants per $\mathrm{F}_{3}$ family was used, and the results were grouped into intervals of 0.1 (abscissa).
Phenotypes of parental lines and $\mathrm{F}_{3}$ population.

The resistance of the cultivar Hawaii7996 and susceptibility of WVa700 to bacterial wilt was confirmed in a greenhouse test with the Taiwanese bacterial strain Pss4 as an inoculum. Wilting of these control lines was also compared with that of L285, a tomato accession resistant to bacterial strain UW364 (Danesh et al. 1994) and L390, a tomato line routinely used as a susceptible control at the AVRDC in Taiwan (Fig. 2). Both WVa700 and L390 were very susceptible (about 95\% of the plants had died by the end of the test) although the development of wilting symptoms progressed a little more rapidly in L390 in the middle of the test than in WVa700. L285 showed an intermediate level of resistance. About $90 \%$ of Hawaii7996 remained healthy, and the $\mathrm{F}_{3}$ population showed an intermediate level of resistance $(2,108 / 3,956$, i.e., $53 \%$, of plants were healthy) However, in contrast to plants from seed of the same $\mathrm{F}_{3}$ population in Guadeloupe (Thoquet et al. 1996b), the distribution of resistance appeared to be bimodal (Fig. 3), suggesting that a locus with a major effect might be present.

\section{Genetic mapping of resistance to bacterial wilt.}

After a preliminary study with various ways of treating the data collected over the course of the disease resistance test, two notation methods were retained for genetic mapping of resistance to bacterial wilt. In the first, the proportion of symptomatic plants (PW) in each family was used, as described previously (Thoquet et al. 1996b). In the second, the area under the disease progression curve (AUDPC; see Materials and Methods) was used.

Firstly, we compared the two methods of data treatment with data collected at the end of the resistance test (28 days after inoculation [d.a.i.]). In both cases, by far the strongest markerresistance association was with TG564 on chromosome 12, explaining from $70 \%$ (PW, 21 d.a.i.) to $74 \%$ (AUDPC) of the genetic variation present, and this must therefore be considered a major locus. AUDPC gave a slightly higher LOD value than PW (Table 1). The 95\% confidence limits for the position of this QTL (see Materials and Methods) are within the 12-cM interval from 4 to $16 \mathrm{cM}$ distal from TG564 (Fig. 4).

Since this QTL is very large, the $x$ LOD support interval, i.e. the genomic region including all map positions flanking the position of the LOD score maximum such that the decrease in LOD score is less than $x$, is a 95\% confidence interval when $x$ is calculated with the $95 \%$ quantile of the $\chi^{2}$ distribution (Mangin et al. 1994). As there are two parameters for the QTL effects in an $\mathrm{F}_{2}$ population, a $\chi^{2}$ distribution with $2 \mathrm{df}$

Table 1. LOD ( $\log _{10}$ of the odds ratio) scores observed during the resistance test ${ }^{\mathrm{a}}$

\begin{tabular}{|c|c|c|c|c|c|c|c|c|c|c|}
\hline \multirow[b]{3}{*}{ Linkage group } & \multicolumn{6}{|c|}{ Time / number of days after inoculation } & & & & \\
\hline & \multicolumn{5}{|c|}{ PW } & AUDPC & \multicolumn{4}{|c|}{ Threshold LOD for given probabilities ${ }^{b}$} \\
\hline & 7 & 10 & 14 & 21 & 28 & 28 & $5 \%$ & $1 \%$ & $0.5 \%$ & $0.1 \%$ \\
\hline 2 & 2.3 & 1.5 & 2.0 & 2 & 1.95 & 1.6 & 1.3 & 2.0 & 2.3 & 3.0 \\
\hline 6 & 0.6 & 2.1 & 3.7 & 4.3 & 5.5 & 3.8 & 2.2 & 3.1 & 3.4 & 4.1 \\
\hline 8 & 0.8 & 1.5 & 3.5 & 1.8 & 1.8 & 1.8 & 1.7 & 2.4 & 2.7 & 3.4 \\
\hline $12^{\mathrm{c}}$ & 6.5 & 16.0 & 22.2 & 24.1 & 23.2 & 25.5 & 2.0 & 2.8 & 3.1 & 3.8 \\
\hline
\end{tabular}

${ }^{a}$ Maximum LOD scores associated with the chromosomal regions shown (Figures 1 and 4) at different times after inoculation after multiple qualitative trait loci (QTL) analysis with a cofactor on chromosome 12 (TG564), using different measures for symptoms: PW = proportion of wilted plants, AUDPC $=$ area under the disease progress curve.

${ }^{\mathrm{b}}$ Calculated according to Rebai et al. (1994).

${ }^{\mathrm{c}}$ Without cofactor (the major effect). 
must be used. This leads to an LOD support interval of 1.3 $\left(1.3=0.217 \chi_{(2) 95 \%}^{2}=0.217 \times 5.99\right)$.

This association was not significant when the same population was tested in Guadeloupe with bacterial strain GMI8217 (Thoquet et al. 1996b; J. Olivier, P. Thoquet, L. Sauviac, and N. H. Grimsley, unpublished data), indicating strongly that it is probably specific for the bacterial strain Pss4. As in Guadeloupe, we now find that in Taiwan with strain Pss4 many markers on chromosome 6 are associated with resistance, but their contribution to resistance is less important, most of the variation being absorbed by the locus on chromosome 12 . PW was more powerful as a means of detecting these associations than AUDPC, and also slightly better for detecting weaker putative QTL (Table 1). As in Guadeloupe (Thoquet et al. 1996b), a possible weak QTL was observed on chromosome 8 , but in contrast to the test done in Guadeloupe, the association of markers on chromosome 3 in Taiwan with resistance was not significant at the $1 \%$ threshold level at the end of the test. A possible weak QTL was provisionally assigned to the bottom of chromosome 2 (GP504) but, in contrast to the other
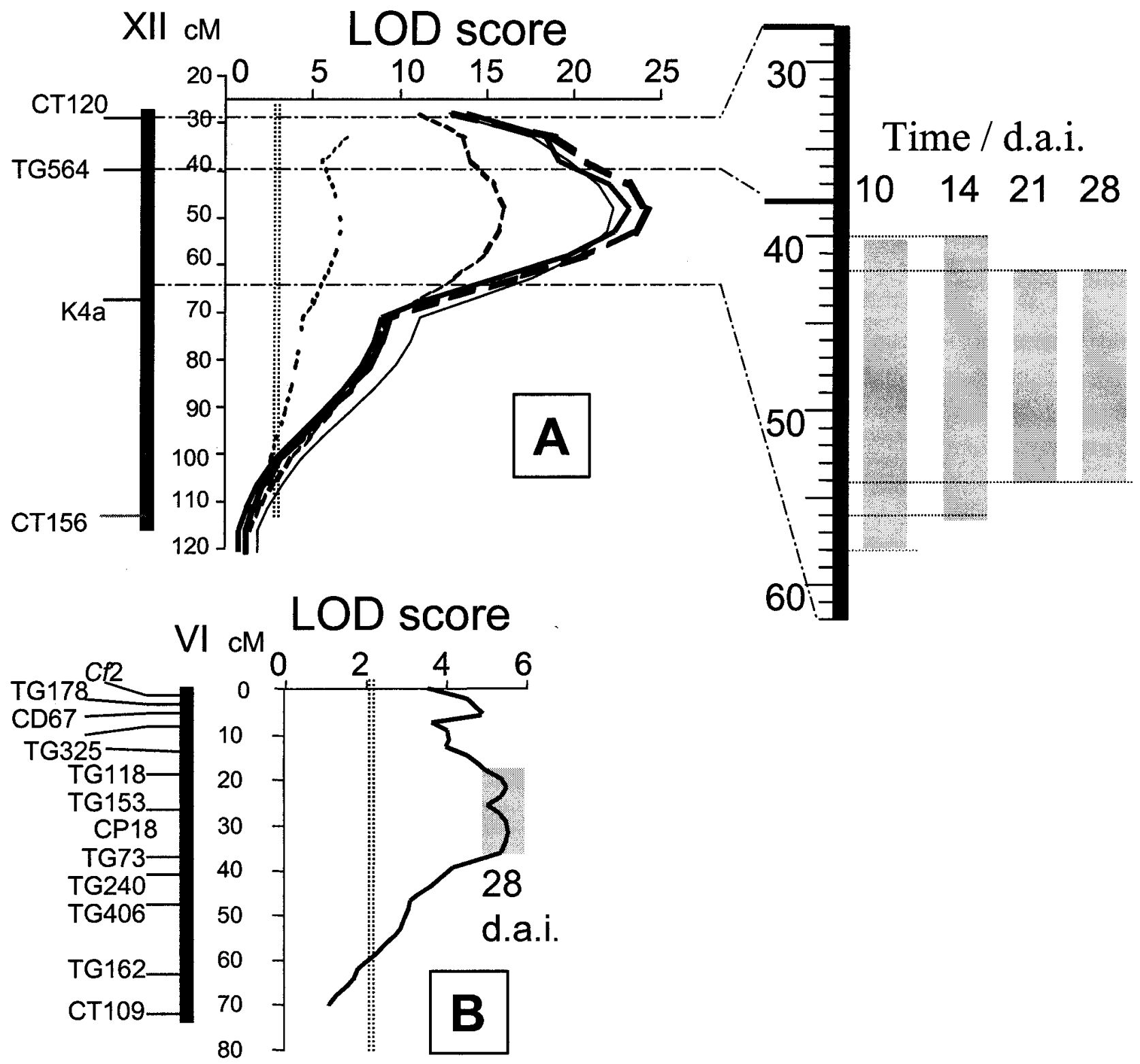

Fig. 4. LOD ( $\log _{10}$ of the odds ratio) score scans. Map distances (cM) are shown alongside the schematic representations of chromosomes (bold straight lines with probe names indicated) with LOD score values on the ordinates. A double dotted straight line indicates the $99 \%$ confidence level for the presence of a quantitative trait locus (QTL), and the $95 \%$ confidence limits for the map position of a QTL at the time point studied (numbers indicate days after inoculation [d.a.i.]) are shown as a gray boxes. A, Chromosome 12. Different curves show results of analysis at different d.a.i. with the pathogen: 7 d.a.i., fine dotted line; 10 d.a.i., fine dashed line; 14 d.a.i., fine continuous line; 21 d.a.i., thick dashed line; 28 d.a.i., thick continuous line. The probe CT120 is arbitrarily positioned at $28 \mathrm{cM}$ according to the reference interspecific map (Tanksley et al. 1992). An expanded map of the region of interest showing 95\% confidence intervals of the QTL is on the right. B, Chromosome 6 with a multiple QTL model (MQM) cofactor (van Ooijen and Maliepaard 1996) placed on the marker TG564 (on chromosome 12, not shown). 
loci, here resistance was carried by the WVa700 allele and the LOD score was decreased after multiple QTL model (MQM) analysis (from 3.2 to 2.3 ).

\section{Temporal analysis of the development of loci associated with bacterial wilt.}

Temporal analysis, with data collected at six different time points during the development of symptoms, showed that the major QTL on chromosome 12 could be detected as early as 7 d.a.i. (at 7 d.a.i. $\mathrm{LOD}=6.5$ at $50 \mathrm{cM}$; Table 1 and Fig. 4A). By 14 d.a.i., the effect of a QTL had already developed to almost its maximum, whereas the QTL on chromosome 6 had only just begun to become significant. At this time point, the weak QTL on chromosome 8 was at a maximum (LOD $=3.5)$. By the end of the test, many markers spanning the upper 40 $\mathrm{cM}$ of chromosome 6 were significantly associated with resistance (Fig. 4B). The association with markers on chromosome 8 , was, however, reduced at the end of the test.

\section{Multiple QTL analysis.}

Since the trait PW showed more significant marker associations than AUDPC with all of the associations observed except for the one on chromosome 12 (which only showed a small difference), PW was chosen for the subsequent analyses. In order to eliminate erroneous associations and to test the hypotheses of one or two QTL on chromosome 6, multiple QTL mapping was performed (van Ooijen and Maliepaard 1996). With the marker TG564 (closest to the main effect; Fig. 4A) as a cofactor, the LOD scores of markers on chromosome 6 increased considerably, broadening further the QTL peak and increasing especially the significance of associations around $30 \mathrm{cM}$ on the curve, with the maximum LOD rising from $L O D=4.1$ to $L O D=5.5$ (Fig. 4B). The $95 \%$ confidence limit interval for the map position of this QTL was calculated with asymptotically similar statistics (Cierco and Mangin 1996). To permit construction of the confidence interval a threshold for the test was first established, by the method developed for a backcross (Mangin and Goffinet 1997) and according to Davies's (1987) approximation. TG564 was then used as a cofactor on the results at 28 d.a.i., allowing the QTL to be placed in an interval of $14 \mathrm{cM}$ starting at $24.6 \mathrm{cM}, 7 \mathrm{cM}$ from TG153 and ending on TG240 (39 cM).

Since the LOD score curve was broad and included a shoulder close to $C f-2$, and since a second QTL controlling bacterial wilt resistance was previously detected on this chromosome (Mangin et al. 1999), we analyzed the data for the possible presence of a second locus. MQM analysis (van Ooijen and Maliepaard 1996) with cofactors on the markers TG564 and TG73 gave a LOD maximum 2.3 around $5 \mathrm{cM}$, and the 2QM ("two-QTL model"; Goffinet and Mangin 1998) gave a LOD value of 1.93, neither of these values being sufficient to support the hypothesis of a second QTL. A LOD score of more than 2.97, obtained by Monte Carlo simulation, (B. Mangin, unpublished data) would be required to accept the hypothesis of 2 loci with $95 \%$ confidence given our experimental constraints. However, the 2QM test predicted the possible presence of two QTL, albeit at a reduced level of confidence ( $80 \%$ by Monte Carlo simulation), one at the $C f-2$ locus ( $0 \mathrm{cM}$ on this map) and the other $1 \mathrm{cM}$ away from TG73, in close agreement with the map positions of the QTL observed in Guadeloupe (Mangin et al. 1999).

\section{DISCUSSION}

While the great majority of linkage groups shown in our analysis can be identified with some certainty because they contain numerous landmark probes that have been located on other maps of tomato and potato, identification of a few of the linkage groups should be interpreted more cautiously, especially since RFLP probes can often identify more than one locus. Thus, the isolated markers on the bottom of chromosome 2 and the bottom of chromosome 4, and the pair of markers on the top of chromosome 12, were assigned provisionally to these map positions with the colinearity with the potato genome as a guide. On the top of chromosome 8, CD40 is the only common landmark. On chromosome 12, CT120 and CT156 provide landmarks, together unambiguously identifying this linkage group, whereas TG564 was previously mapped on chromosome 3 (Tanksley et al. 1992). However, the TG564 probe hybridizes to several bands, and the polymorphic allele of TG564 in our material is unlikely to reside on chromosome 3 since it does not show linkage to GP226, CP6, and TG515, which are all found on chromosome 3 in other crosses (Gebhardt et al. 1991; Tanksley et al. 1992). We thus assigned this allele to chromosome 12 , since it is clearly linked to CT120 (LOD = 31.7).

In view of the predominance of the QTL governing resistance to bacterial wilt on chromosome 6 in several previous studies (Danesh et al. 1994; Thoquet et al. 1996a, 1996b), we were surprised to discover that most of the resistance against Pss 4 could be explained by a locus on chromosome 12. Time course analysis shows that this association is already detectable at 7 d.a.i. and the maximum resolution for the position of the QTL is reached at 21 d.a.i.

Although chromosome 6 still contributes to resistance against bacterial wilt strain Pss4, its importance is reduced, when this study is compared with the previous studies. There was no evidence that the locus on chromosome 12 is epistatic to the locus on chromosome 6 in our results when the data were tested by analysis of variance (Table 2). In contrast to previous work (Thoquet et al. 1996b; Mangin et al. 1999), and after analysis for the possible presence of more than one QTL on chromosome 6, the data can be explained by a single QTL near to TG73, once the variation associated with the major QTL present on chromosome 12 has been removed from the population (Fig. 4). However, although the LOD score of the $2 \mathrm{QM}$ test was not significant (see above), it predicts map positions for the possible presence of two QTL that closely agree with those of the two loci detected after analysis of data from this population tested in Guadeloupe (Mangin et al. 1999). We thus hypothesize that a second QTL close to $C f-2$ may be present, but that it lies below the threshold for detection. However, in contrast to the current results, the QTL observed in Guadeloupe (Thoquet et al. 1996b) near to $C f-2$ is larger than that close to TG73.

Table 2. Test for interaction between resistance loci on chromosomes 6 and 12

\begin{tabular}{lccccc}
\hline $\begin{array}{l}\text { Interaction } \\
\text { analyzed }\end{array}$ & df & Sum of sq & RSS & F value & $\boldsymbol{P ( F )}$ \\
\hline None & & & 6.520506 & & \\
$C f-2 *$ TG564 & 4 & 0.0612243 & 6.581731 & 0.338022 & 0.8519625 \\
TG73* TG564 & 4 & 0.3153349 & 6.835841 & 1.740978 & 0.1441622 \\
$C f-2 *$ TG73 & 4 & 0.0306113 & 6.551118 & 0.169006 & 0.9538801 \\
\hline
\end{tabular}


We did not find any association between resistance in Taiwan and RFLP markers assigned to chromosome 3, as previously noted after inoculation with the strain GMI8217 in Guadeloupe and Toulouse (Thoquet et al. 1996b), so this might be an environment- or strain-specific effect.

No association was found with chromosome 4 , but in the current study we used almost exclusively codominant RFLP markers, whereas in previous analyses (Thoquet et al. 1996a, 1996b) dominant RAPD markers were included, and the data were not normalized by transformation $(\arcsin \sqrt{ } x)$ before use, so these results are not directly comparable. Indeed, we now believe that the weak associations previously seen with markers on chromosome 4 after inoculation with strain GMI8217 (Thoquet et al. 1996a, 1996b) may be type I errors. More markers for chromosomes 8 and 12 are desirable for the current study, but our efforts to extend the map have met with limited success since there is little polymorphism in this material (Thoquet et al. 1996a). However, practically all of the genetic variation is accounted for, and we feel it unlikely that other important associations remain undiscovered. Further, more detailed analysis must await the availability of new genetic material and/or more polymorphic DNA markers.

Strain or race specificity is a characteristic that is classically associated with single-gene dominant or "vertical" resistance in the literature (Flor 1971), current dogma being that specific pathogen avirulence gene products are recognized by corresponding dominant plant resistance gene alleles. Quantitative or "horizontal" resistance, on the other hand, is associated with numerous genes having smaller effects but acting against a broad spectrum of pathogenic races. Recent work, however, has revealed that quantitative resistance may also be strain specific in some cases in which QTL are responsible for the resistance (Kreike et al. 1994; Leonards-Schippers et al. 1994; Concibido et al. 1996). Here, we demonstrate that much of the quantitative genetic variation giving resistance to $R$. solanacearum is most likely strain specific, since the locus on chromosome 12 active against Pss4 is not significantly associated with resistance to strain GMI8217. Although it remains possible that this allele governs specificity of resistance to an uncharacterized environmental effect, such as soil type or temperature, we consider this alternative to be much less likely. Final confirmation of strain specificity requires further experimental work. Likewise, the weak QTL found on chromosome 3 in Guadeloupe (Thoquet et al. 1996b) and in Toulouse (Thoquet et al. 1996a) giving resistance to GMI8217 is not active against Pss4 in Taiwan. In our material, the QTL near to TG73 identified on chromosome 6 is active against both strains GMI8217 and Pss4. However, another locus close to $C f$-2 actively defends against attacks by GMI8217 in Guadeloupe (Thoquet et al. 1996b; Mangin et al. 1999) but probably lies below the limit of detection in Taiwan (see above) after inoculation with Pss4, since in the latter case the hypotheses of one locus close to TG73 is sufficient to explain the observed data. In contrast to our work, which shows the QTL near TG73 to give resistance to two strains, previous reports show a strain-specific locus is present in the tomato cultivar L285 in this region, giving resistance to UW364 but not to Pss4 or Pss97 (Danesh et al. 1994; Danesh and Young 1994). Thus, this locus may be a different gene or allele than the one described by Danesh et al. (1994) and Danesh and Young (1994), and it seems likely that different alleles or a cluster of genes conferring resistance to different strains of $R$. solanacearum might exist around $35 \mathrm{cM}$ on chromosome 6 . Given the abundance of strain-specific interactions present in the few studies done by genetic analysis of tomato populations with molecular markers, we speculate that the molecular mechanism of resistance controlled by many of the QTL may resemble those found for single "gene for gene" resistance. Singlegene resistance loci and quantitative resistance loci have been observed to map in the same genomic region (Yu et al. 1991). Many environment-specific QTL affecting response to pathogens (for a review see Young 1996) might therefore be manifestations of strain-specific effects in field trials where it is often not possible to control the nature of the inoculum. Indeed, there is good evidence from recent molecular analyses that some members of the clusters in a gene family, one allele of which confers complete dominant resistance, can confer partial resistance to a given pathogen (Simons et al. 1998; Wang et al. 1998b). The "global" resistance of cultivar Hawaii7996 in many worldwide geographic locations (Wang et al. 1998a) might thus represent a collection of partial resistance loci (Danesh et al. 1994; Thoquet et al. 1996a, 1996b; Mangin et al. 1999; this work) with different strain specificities (Danesh and Young 1994; Mangin et al. 1999; this work). If this is the case, then the durability of host plant polygenic resistance may stem from (i) the multiplicity of loci contributing an effect and (ii) the reduced selective pressure on a pathogen to break a partial resistance or tolerance, rather than on a mechanistically different response to single-gene resistance. It is doubtful that any one tomato line exists that carries resistance to all strains of $R$. solanacearum, since tomato breeding programs are usually specific for certain geographic locations and hundreds of different strains of the pathogen are present worldwide. Indeed, recent tests show that Hawaii 7996 is susceptible to certain strains (Jaunet and Wang 1999), underlining the need for concerted worldwide efforts in the identification of new sources of resistance and production of resistant varieties.

\section{MATERIALS AND METHODS}

\section{Pathogen culture.}

The $R$. solanacearum (previously classified as Pseudomonas solanacearum or Burkholderia solanacearum; Yabuuchi et al. 1995) strain Pss4, endemic to Taiwan, was used to inoculate the plants. This race 1 biovar 3 strain is highly aggressive (Jaunet and Wang 1999) and has been used at the AVRDC for routine screening and breeding for bacterial wilt resistance (Hanson et al. 1998). The bacteria were grown on plates containing 523-medium (Kado and Heskett 1970) at $30^{\circ} \mathrm{C}$ for $24 \mathrm{~h}$, harvested with glass slides, suspended in water, and adjusted to $\mathrm{OD}_{600}=0.3$ (about $10^{8} \mathrm{CFU}$ per $\mathrm{ml}$ ).

\section{Plant materials.}

Tomatoes were grown individually in $7.62-\mathrm{cm}$-diameter plastic pots. The potting mixture, consisting of sand, soil, rice husks, and compost (1:3:1:1), was pasteurized with steam prior to use. The lines Hawaii7996 (resistant to bacterial wilt), L285 (resistant), WVa700 (susceptible), and L390 (susceptible) were grown as homozygous controls. $\mathrm{F}_{3}$ seed were obtained from the cross between Hawaii7996 and WVa700 made previously (Thoquet et al. 1996a). 


\section{Resistance tests.}

These were conducted in the greenhouse at the AVRDC, Taiwan, with the bacterial strain Pss4. Owing to the limited space available, the resistance tests were done in three successive replicates (test 1: 191 families, 1,370 plants; test 2: 188 families, 1,307 plants; test 3: 178 families, 1,277 plants), each replicate containing representatives of all of the controls and about 8 plants of each $\mathrm{F}_{3}$ family. Plants were assigned unique identification numbers and arranged randomly before inoculation to reduce possible effects of small variations in the development of disease and eliminate any bias in disease evaluation. Four-week-old seedlings, at approximately the five-leaf stage, were inoculated by drenching the soil surface near the base of each plant with $30 \mathrm{ml}$ of the bacterial suspension prepared as above. Plant roots were not wounded before inoculation. The mean maximum and minimum temperatures and relative humidities during the period of each replicate were $30.7 / 22.3^{\circ} \mathrm{C}$ and $77.3 / 46.2 \%$ for the first replicate, $31.7 / 22.8^{\circ} \mathrm{C}$ and $82.8 / 50.7 \%$ for the second replicate, and $31.8 / 23.3^{\circ} \mathrm{C}$ and $82.7 / 52.7 \%$ for the third replicate. Observations for bacterial wilt were carried out at $4,7,10,14,21$, and 28 d.a.i. according to the following scale: 0 , no visible wilt; 1 , one leaf wilted; 2 , two or three leaves wilted; 3 , all except the top leaves wilted; 4, all leaves wilted; and 5, dead (collapsed stem).

\section{Analysis of data.}

Data from the three successive tests were collected under similar greenhouse conditions. Almost the complete $F_{3}$ population was represented in each test and all of the data were bulked together. A few families were poorly represented due to low seed set (12 families with 0 to 9 plants total) and these were not included, leaving a population of $3,934 \mathrm{~F}_{3}$ plants representing $188 \quad \mathrm{~F}_{2}$ lines that were analyzed with molecular markers. Two methods for treating the data were used for quantitative trait analysis: (i) PW ("proportion of wilted" plants). Plants were scored either as healthy (scale 0) or wilted (scale 2 to 5). The proportion of plants wilted for each family, $p$, was then used, after transformation with $y=\arcsin \sqrt{ } p$ to improve the normality of the distribution, as the statistic for QTL analysis. This notation permitted genetic analysis at the different time points during the analysis. (ii) AUDPC. The mean (AUDPC from the three tests was calculated and used. The AUDPC was calculated with AUDPC $=\Sigma_{\mathrm{i}=1 \text { to } n-1}\left[\left(\mathrm{Y}_{\mathrm{i}+1}\right.\right.$ $\left.\left.+\mathrm{Y}_{\mathrm{i}}\right) / 2\right]\left[\mathrm{X}_{\mathrm{i}+1}-\mathrm{X}_{\mathrm{i}}\right]$, in which $\mathrm{Y}_{\mathrm{i}}=$ the percentage of healthy plants at the $\mathrm{i}$ th observation ( $\mathrm{i}=1$ being the first observation point at time zero), $\mathrm{X}_{\mathrm{i}}=$ time (days) at the $\mathrm{i}$ th observation, and $n=$ total number of observations. Thus, for example, in a test lasting 28 days in which all plants of a family remained healthy, a maximum score of 2,800 was obtained. Map distances (Haldane) were calculated with the Mapmaker (Lander et al. 1987) software. The length of some linkage groups was longer than that calculated by the JoinMap software (Stam 1993). QTL analysis was performed with MapQTL (van Ooijen and Maliepaard 1996) and MapmakerQTL. In order to perform MQM analysis with MapQTL, putative QTL were first identified by interval mapping with both MapQTL and MapmakerQTL. The closest marker to a QTL maximum was then used as a cofactor for the subsequent MQM analysis, thus removing (by calculation) the variation present in the population due to that QTL. This procedure reduces the residual variation present in the population when the MQM search is made, enhancing the power of detection for other QTL.

\section{ACKNOWLEDGMENTS}

We thank M. Arlat and L. Godiard for critical reading of the manuscript, the laboratories of Steve Tanksley, Christiane Gebhardt, and Jonathan Jones for gifts of RFLP probes, and Mei-hong Chuang for help with greenhouse resistance tests. We acknowledge financial support to N. G. provided by the European Community (ERBCHRXCT930170) and Région Midi-Pyrénées (3172A)., and to J.-F. W. by the National Science Council of Taiwan (NSC 89-2313-B-125-001).

\section{LITERATURE CITED}

Alfano, J. R., and Collmer, A. 1997. The type III (Hrp) secretion pathway of plant pathogenic bacteria: trafficking harpins, Avr proteins, and death. J. Bacteriol. 179:5655-5662.

Buddenhagen, I., and Kelman, A. 1964. Biological and physiological aspects of bacterial wilt caused by Pseudomonas solanacearum. Annu. Rev. Phytopathol. 2: 203-230.

Cierco, C., and Mangin, B. 1996. Construction of confidence intervals for quantitative trait loci in $\mathrm{F}_{2}$ populations. Biometrics 52:1268-1282.

Concibido, V., Young, N. D., Lange, D. A., Denny, R. L., Danesh, D., and Orf, J. H. 1996. Targeted comparative genome analysis and quantitative mapping of a major partial-resistance gene to the soybean cyst nematode. Theor. Appl. Genet. 93:234-241.

Danesh, D., Aarons S., McGill, G. E., and Young, N. D. 1994. Genetic dissection of oligogenic resistance to bacterial wilt in tomato. Mol. Plant-Microbe Interact. 7:464-471.

Danesh, D., and Young, N. D. 1994. Partial resistance loci for tomato bacterial wilt show differential race specificity. Tomato Genet. Coop. Rep. 44:12-13.

Davies, R. B. 1987. Hypothesis testing when nuisance parameter is present only under the alternative. Biometrika 64:247-254.

Deslandes, L., Pileur, F., Liaubet, L., Camut, S., Can, C., Williams, K., Holub, E., Beynon, J., Arlat, M., and Marco, Y. 1998. Genetic characterization of RRS1, a recessive locus in Arabidopsis thaliana that confers resistance to the bacterial soilborne pathogen Ralstonia solanacearum. Mol. Plant-Microbe Interact. 11:659-667.

Flor, H. H. 1971. Current status of the gene-for-gene concept. Annu. Rev. Phytopathol. 9:275-296.

Gebhardt, C., Ritter, E., Barone, A., Debener, T., Walkemeier, B., Schachtschabel, U., Kaufmann, H., Thompson, R. D., Bonierbale, M. W., Ganal, M. W., Tanksley, S. D., and Salamini, F. 1991. RFLP maps of potato and their alignment with the homologous tomato genome. Theor. Appl. Genet. 83:49-57.

Goffinet, B., and Mangin, B. 1998. Comparing methods to detect more than one QTL on a chromosome. Theor. Appl. Genet. 96:628-633

Gough, C. L., Genin, S., Zischek, C., and Boucher, C. A. 1992. hrp genes of Pseudomonas solanacearum are homologous to pathogenicity determinants of animal pathogenic bacteria and are conserved among plant pathogenic bacteria. Mol. Plant-Microbe Interact. 5:384389.

Grimault, V., Prior, P., and Anaïs, G. 1995. A monogenic dominant resistance of tomato to bacterial wilt in Hawaii7996 is associated with plant colonization by Pseudomonas solanacearum. J. Phytopathol. 143:349-352.

Hanson, P. M., Licardo, O., Hanudin, Wang, J. F., and Chen, J.-T. 1998. Diallel analysis of bacterial wilt resistance in tomato derived from different sources. Plant Dis. 82:74-78.

Hayward, A. C. 1991. Biology and epidemiology of bacterial wilt caused by Pseudomonas solanacearum. Annu. Rev. Phytopathol. 29: 65-87.

Jaunet, T. X., and Wang, J.-F. 1999. Variation in genotype and aggressiveness of Ralstonia solanacearum race 1 isolated from tomato in Taiwan. Phytopathology 89:320-327.

Kado, C. I., and Heskett, M. G. 1970. Selective media for isolation of Agrobacterium, Corynebacterium, Erwinia, Pseudomonas, and Xanthomonas. Phytopathology 60:969-976.

Kelman, A. 1953. The bacterial wilt caused by Pseudomonas solanacearum. N.C. Agric. Exp. St. Tech. Bull. 99. 
Kreike, C. M., de Koning, J. R. A., Vinke, J. H., van Ooijen, J. W., and Stiekema, W. J. 1994. Quantitatively-inherited resistance to Globodera pallida is dominated by one major locus in Solanum spegazzinii. Theor. Appl. Genet. 88:764-769.

Lander, E. S., Green, P., Abrahamson, J., Barlow, A., Daly, M. J., Lincoln, S. E., and Newburg, L. 1987. Mapmaker: An interactive computer package for constructing primary genetic linkage maps of experimental and natural populations. Genomics 1:174-181.

Leonards-Schippers, C., Gieffers, W., Schaferpregl, R., Ritter, E., Knapp, S. J., Salamini, F., and Gebhardt, C. 1994. Quantitative resistance to Phytophthora infestans in potato - a case study for QTL mapping in an allogamous plant species. Genetics 137:67-77.

Mangin, B. and Goffinet, B. 1997. Comparison of several confidence intervals for QTL location. Heredity 78:345-353.

Mangin, B., Goffinet, B., and Rebai, A. 1994. Constructing confidence intervals for QTL location. Genetics 138:1301-1308.

Moreau, P., Thoquet, P., Olivier, P., and Grimsley, N. 1998. Genetic mapping of $P h-2$, a single locus controlling partial resistance to Phytophthora infestans in tomato. Mol. Plant-Microbe Interact. 11:259269.

Mangin, B., Thoquet, P., Olivier, J., and Grimsley, N. H. 1999. Temporal and multiple quantitative trait loci analyses of resistance to bacterial wilt in tomato permit the resolution of linked loci. Genetics 151:11651172.

Rebai, A., Goffinet, B., and Mangin, B. 1994 Approximate threshold of interval mapping tests for QTL detection. Genetics 138:235-240.

Schmit, J. 1978. Microscopic study of early stages of infection by Pseudomonas solanacearum E.F.S. on "in vitro" grown tomato seedlings. Pages 841-856 in: Proc. Int. Conf. Plant Pathol. Bacteriol., 4th.

Simons, G., Groenendijk, J., Wijbrandi, J., Reijans, M., Groenen, J., Diergaarde, P., Van der Lee, T., Bleeker, M., Onstenk, J., de Both, M., Haring, M., Mes, J., Cornelissen, B., Zabeau, M., and Vos, P. 1998 Dissection of the Fusarium $I 2$ gene cluster in tomato reveals six homologs and one active gene copy. Plant Cell 10:1055-1068.

Stam, P. 1993. Construction of integrated genetic linkage maps by means of a new computer package: JoinMap. Plant J. 3:739-744.

Tanksley, S. D., Ganal, M. W., Prince, J. P., Devicente, M. C., Bonierbale, M. W., Broun, P., Fulton, T. M., Giovannoni, J. J., Grandillo, S., Martin, G. B., Messeguer, R., Miller, J. C., Miller, L., Paterson, A. H., Pineda, O., Roder, M. S., Wing, R. A., Wu, W., and Young, N. D. 1992. High density molecular linkage maps of the tomato and potato genomes. Genetics 132:1141-1160.

Thoquet, P., Olivier, J., Sperisen, C., Rogowsky, P., Laterrot, H., and Grimsley, N. 1996a. Quantitative trait loci determining resistance to bacterial wilt in tomato cultivar Hawaii7996. Mol. Plant-Microbe Interact. 9:826-836

Thoquet, P., Olivier, J., Sperisen, C., Rogowsky, P., Prior, P., Anaïs, G., Mangin, B., Bazin, B., Nazer, R., and Grimsley, N. 1996b. Polygenic resistance of tomato plants to bacterial wilt in the French West Indies. Mol. Plant-Microbe Interact. 9:837-842.

Van Gijsegem, F., Genin, S., and Boucher, C. A. 1993. Conservation of secretion pathways for pathogenicity determinants of plant and animal bacteria. Trends Microbiol. 1:175-180.

van Ooijen, J. W., and Maliepaard, C. 1996. MapQTL version 3.0: Software for the calculation of QTL positions on genetic maps. CPRODLO, Wageningen, The Netherlands.

Vasse, J., Frey, P., and Trigalet, A. 1995. Microscopic studies of intercellular infection and protoxylem invasion of tomato rests by Pseudomonas solanacearum. Mol. Plant-Microbe Interact. 8:241-251.

Wang, J. F., Hanson, P. M., and Barnes, J. A. 1998a. Worldwide evaluation of international set of resistance sources to bacterial wilt in tomato. Pages 269-275 in: Bacterial Wilt Disease: Molecular and Ecological Aspects. P. Prior, C. Allen, and J. Elphinstone, eds. Springer, Berlin.

Wang, L. W., Ruan, D.-L., Song, W.-Y., Sideris, S., Chen, L. L., Pi, L.A., Zhang, S., Zhang, Z., Fauquet, C., Gaut, B. S., Whalen, M. C., and Ronald, P. C. 1998 b. Xa21D encodes a receptor-like molecule with a leucine-rich repeat domain that determines race-specific recognition and is subject to adaptive evolution. Plant Cell 10:765-779.

Yabuuchi, E., Kosako, Y., Yano, I., Hotta, H., and Nishiuki, Y. 1995. Transfer of two Burkholderia and an Alcaligenes species to Ralstonia gen. nov.: Proposal of Ralstonia pickettii (Ralston, Palleroni and Duodoroff 1973. comb. nov. and Ralstonia eutropha (Davis 1969) comb. nov. Microbiol. Immunol. 39:897-904.

Yang, C.-H., and Ho, G.-D. 1998. Resistance and susceptibility of Arabidopsis thaliana to bacterial wilt caused by Ralstonia solanacearum. Phytopathology 88:330-334.

Young, N. D. 1996. QTL mapping and quantitative disease resistance in plants. Annu. Rev. Phytopathol. 34:479-501.

Yu, Z. H., Mackill, D. J., Bonman, J. M., and Tanksley, S. D. 1991. Tagging genes for blast resistance in rice via linkage to RFLP markers. Theor. Appl. Genet. 81:471-476. 